\title{
An Evaluation of Homogeneity and Heterogeneity in Metals Processed by High-Pressure Torsion
}

\author{
R.B. Figueiredo ${ }^{a}$, M. KaWASAKI ${ }^{b}$, And T.G. LANGDON ${ }^{b, c, *}$ \\ ${ }^{a}$ Department of Materials Engineering and Civil Construction, Federal University of Minas Gerais \\ Belo Horizonte, MG 31270-901, Brazil \\ ${ }^{b}$ Departments of Aerospace \& Mechanical Engineering and Materials Science \\ University of Southern California, Los Angeles, CA 90089-1453, USA \\ ${ }^{c}$ Materials Research Group, School of Engineering Sciences, University of Southampton \\ Southampton SO17 1BJ, United Kingdom
}

\begin{abstract}
Processing through the use of high-pressure torsion is attracting much attention at the present time because of the potential for achieving exceptional grain refinement. In principle, it appears that the thin disks used for high-pressure torsion processing should exhibit significant heterogeneity in the as-processed condition. However, experiments show that the development of homogeneity or heterogeneity is dependent upon the crystalline structure of the material. For high-purity aluminum the as-processed microstructure is very homogeneous after five or more revolutions of torsional straining but for the magnesium AZ31 alloy there is a considerable degree of heterogeneity in the as-processed disks.
\end{abstract}

PACS: 61.66.Bi, 61.66.Dk

\section{Introduction}

A reduction in grain size leads to higher strength in polycrystalline metals. Therefore, thermo-mechanical treatments are used in the industrial processing of metals in order to achieve significant grain refinement in commercial alloys. However, there is a limitation with these procedures because they generally produce grain sizes of the order of a few micrometers and it is difficult or impossible to use this approach to achieve average grain sizes within the submicrometer range. As a consequence of these limitations, considerable interest has arisen over the last decade in the alternative procedure of processing metals through the application of severe plastic deformation (SPD).

Two typical SPD processing methods currently available are equal-channel angular pressing (ECAP) [1] and high-pressure torsion (HPT) [2] where these techniques are designed to impose very high strains in the processing operation without introducing any significant change in the overall dimensions of the samples. The processing procedures of ECAP and HPT are effective in producing submicrometer arrays of grains or, in some metals, grains within the true nanometer $(<100 \mathrm{~nm})$ range. It was shown through experiments that the grains produced by HPT are generally smaller than those achieved using ECAP [3-5] and, accordingly, HPT processing is therefore advancing rapidly to become a significant processing procedure.

Processing by HPT is generally conducted using a thin disk which is placed between anvils, subjected to a high applied pressure, and then processed by torsional straining through rotation of one of the anvils. The strain

\footnotetext{
* corresponding author; e-mail: langdon@usc.edu
}

imposed in HPT may be estimated using the schematic illustration in Fig. 1 [4]. For a small rotation, d $\theta$, corresponding to a displacement $\mathrm{d} \ell$, it follows that $\mathrm{d} \ell=r \mathrm{~d} \theta$ so that the shear strain, $\mathrm{d} \gamma$, is given by $r \mathrm{~d} \theta / h$ where $r$ and $h$ are the radius and thickness of the disk, respectively. Putting $\theta=2 \pi N$, it follows that the equivalent von Mises strain, $\varepsilon_{\text {eq }}$, is given by an expression of the form $[6-8]$ :

$$
\varepsilon_{\mathrm{eq}}=\frac{2 \pi N r}{h \sqrt{3}}
$$

where $N$ is the number of turns of the anvil. Inspection of Eq. (1) shows that the strain imposed in HPT varies with the position on the disk. Specifically, it reaches a maximum at the edge of the disk whereas the strain is reduced to zero at the center where $r=0$. This suggests that the microstructures introduced in HPT processing will be extremely inhomogeneous and they will vary as a function of the radial position within each disk.

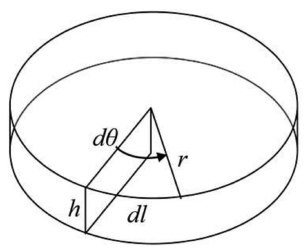

Fig. 1. Parameters used in estimating the total strain in HPT [4].

Despite the implications of inhomogeneity through Eq. (1), in early experiments where HPT was applied to pure nickel it was reported that there was a gradual evolution in structure, as recorded through microhardness measurements, towards a reasonable level of homogeneity throughout the disks. Furthermore, this evolution 
occurred with either increasing applied pressure, $P$, or increasing numbers of revolutions in the processing operation $[4,9]$. Later experiments confirmed this evolution towards homogeneity [10-17] and the evolution process was successfully modeled using strain gradient plasticity theory [18].

The development of homogeneity in HPT disks may be demonstrated most easily by taking a series of hardness measurements across each disk. Nevertheless, these measurements provide information only on the radial distributions of the hardness values on the disk surfaces and they provide no direct information on any variations that may exist within the thickness of each disk. This question has been examined recently in experiments conducted on high-purity aluminum [19] and a magnesium AZ31 alloy $[20,21]$. The results from these experiments are discussed in the following two sections and Sect. 4 provides a direct comparison between these two materials.

\section{HPT processing of high-purity aluminum}

Annealed high-purity (99.99 wt\%) aluminum was used for these tests where the initial grain size was $\approx 1 \mathrm{~mm}$. A series of disks was prepared from the annealed metal having diameters of $10 \mathrm{~mm}$ and thicknesses of $\approx 0.81 \mathrm{~mm}$ and these disks were processed by HPT under quasi-constrained conditions [2] at room temperature using an applied pressure of $P=6.0 \mathrm{GPa}$. The disks were processed for different numbers of turns ranging from $1 / 4$ to 20 revolutions and then the values of the Vickers microhardness were recorded both along diameters of the disks and over the total surfaces. Further details of the experimental procedures were given earlier [19]. To provide comprehensive information on the variation of the hardness values with depth within the disks, three disks were prepared for each of $1 / 4$ and $1 / 2$ turn and hardness measurements were recorded on polished surfaces in the central plane of each disk and at planes within $\approx 200 \mu \mathrm{m}$ of the upper and lower surfaces after HPT processing.

The results are shown in Fig. 2 for hardness measurements taken along the disk diameters after $N=1 / 4$ and $1 / 2$ turn where the upper points are the experimental readings and the lower broken line corresponds to the measured hardness in the annealed condition prior to HPT processing [19]. There are two important conclusions from inspection of Fig. 2. First, all three sets of experimental data are in excellent agreement thereby showing there is no significant variation in hardness through the thickness of each disk. Second, the variations in hardness are symmetrical with respect to the centers of the disks. For all three disks taken through $N=1 / 4$ turn in Fig. 2a, the hardness increases at the outer edge from $\mathrm{Hv} \approx 20$ in the annealed condition to $\mathrm{Hv} \approx 40$. At the center of each disk the hardness also increases but only to $\mathrm{Hv} \approx 30$, and at intermediate distances between the centers and the edges the measurements show the hardness values increase up to a maximum of $\mathrm{Hv} \approx 50$. There is also excellent consistency between all three planes after $N=1 / 2$ turn but the distribution of hardness values is then different. Specifically, there is the same value of
$\mathrm{Hv} \approx 40$ around the edge but an increase to $\mathrm{Hv} \approx 40$ in the center and smaller peaks in the hardness values between the center and the edge but with similar maximum values of $\mathrm{Hv} \approx 50$. The change in the distribution of hardness values between $1 / 4$ and $1 / 2$ turn is consistent with an evolution towards a reasonable level of homogeneity. Further information on the processing of high-purity aluminum in the early stages of HPT is given in an earlier report [22].

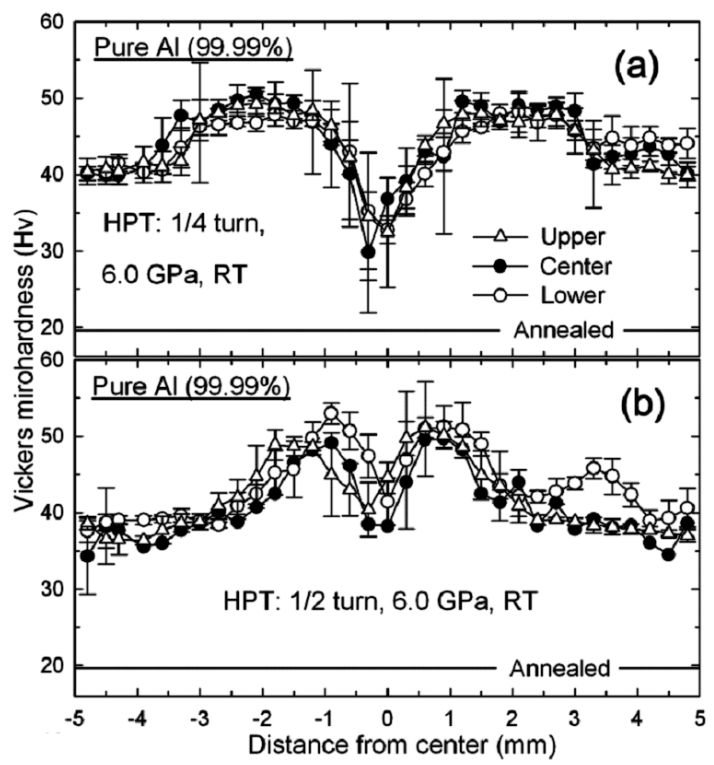

Fig. 2. Variation of the average Vickers microhardness recorded at the upper, center and lower positions with distance from the center of the pure $\mathrm{Al}$ disks after processing by HPT through (a) $1 / 4$ and (b) $1 / 2$ turn [19].

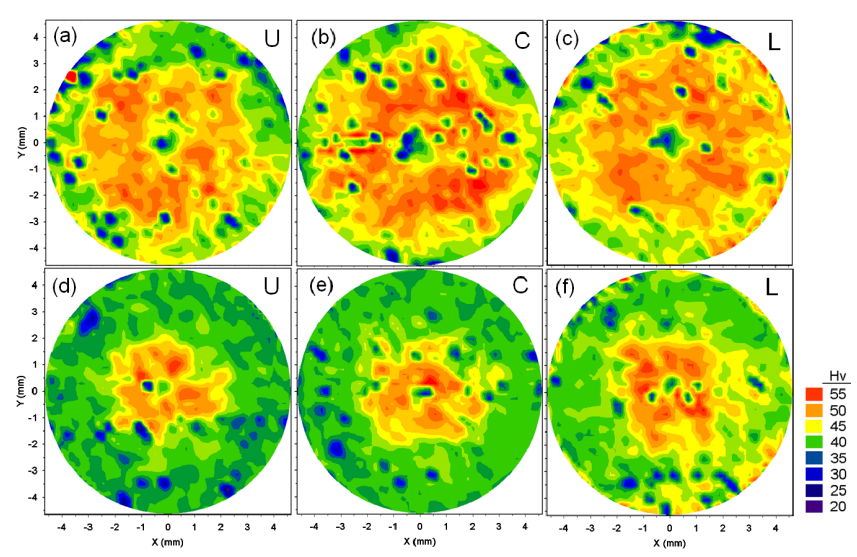

Fig. 3. Color-coded contour maps showing the distributions of the Vickers microhardness values at the upper $(\mathrm{U})$, the center $(\mathrm{C})$, and the lower $(\mathrm{L})$ positions of the pure $\mathrm{Al}(99.99 \%)$ disk surfaces after processing by HPT (6.0 GPa, RT) through (a)-(c) $1 / 4$ turn and (d)-(f) $1 / 2$ turn, respectively [19].

The symmetry in hardness values with respect to the center of each disk is demonstrated in greater detail in the color-coded maps shown in Fig. 3 where the upper row 


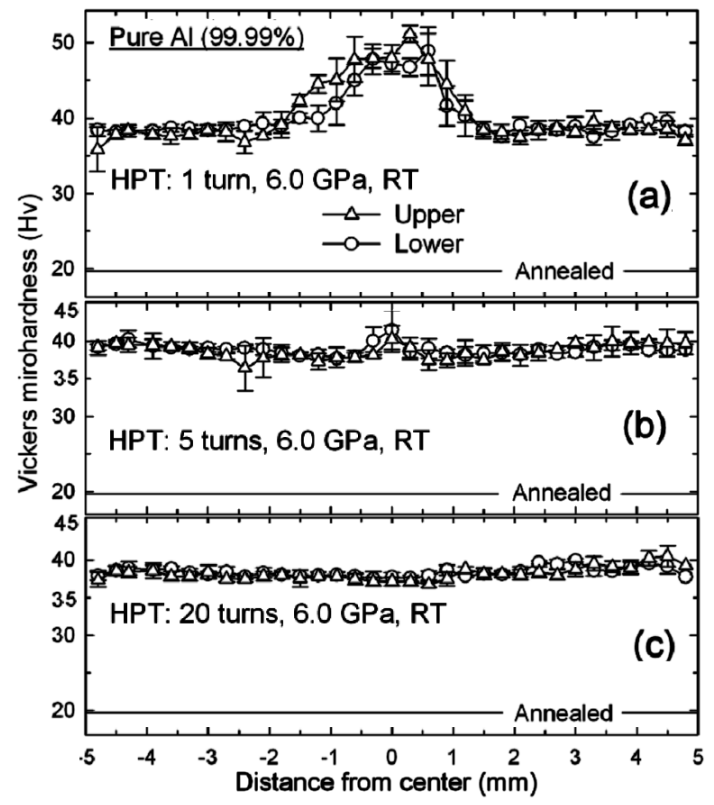

Fig. 4. Variation of the average Vickers microhardness recorded at the upper and lower positions with distance from the center of the pure $\mathrm{Al}$ disk after processing by HPT through (a) 1, (b) 5, and (c) 20 turns [19].

corresponds to the disks processed through $1 / 4$ turn and the lower row corresponds to the disks processed through $1 / 2$ turn: the significance of the colors is given in the color key on the right [19]. From these measurements, it is concluded that there is no significant variation between the different sectional planes for disks of high-purity aluminum processed through the early stages of HPT. Furthermore, the general consistency between each plane of sectioning provides a clear confirmation that the HPT processing was conducted without incurring any significant slippage of the disks [23].

The variation in the hardness values across the diameters of disks after larger numbers of revolutions is shown in Fig. 4 where data are presented for (a) $N=1$ turn, (b) $N=5$ turns and (c) $N=20$ turns, respectively, and the lower lines at $\mathrm{Hv} \approx 20$ again denote the initial annealed condition: for each disk, measurements were taken along linear traverses at $\approx 200 \mu \mathrm{m}$ from the upper and lower surfaces after HPT processing [19]. The plot in Fig. 4 a shows the hardness remains at $\mathrm{Hv} \approx 40$ around the periphery of the disk after $N=1$ turn but there are higher hardness values in the center up to $\mathrm{Hv} \approx 50$. This higher hardness in the central region of the disk is consistent with earlier measurements on high-purity aluminum processed by HPT through 1 turn [12]. After 5 turns, shown in Fig. 4b, there is only a very small area of slightly higher hardness within a region at the center of the disk having a diameter of $<1 \mathrm{~mm}$ and after 20 turns, shown in Fig. 4c, all values of hardness are essentially identical with $\mathrm{Hv} \approx 40$. Thus, the processing of high-purity aluminum by HPT leads to excellent ho- mogeneity throughout the thicknesses of the disks after processing through more than $\approx 5$ revolutions.

\section{HPT processing of a magnesium AZ31 alloy}

It is well known that the processing of magnesium is more difficult than aluminum because the hexagonal crystal structure leads to a limited number of slip systems. The difficulty in processing magnesium by SPD was demonstrated in early experiments using ECAP conducted on pure magnesium and a magnesium alloy [24]. Accordingly, these metals with limited slip systems are termed "difficult-to-work" materials and special techniques are needed in order to successfully process these materials using ECAP [25, 26].

The present experiments were conducted on an extruded commercial AZ31 magnesium alloy containing $3 \% \mathrm{Al}$ and $1 \% \mathrm{Zn}$. In the unprocessed condition, the initial grain size was $\approx 9.4 \mu \mathrm{m}$. Disks were prepared as for high-purity aluminum and these disks were also processed under quasi-constrained HPT conditions [2] at a temperature of $463 \mathrm{~K}$ and with an applied pressure of $6.0 \mathrm{GPa}$. Further details of these experiments are given elsewhere [20, 21]. Separate disks were processed through $1 / 4,1$ and 5 turns and these disks were then sectioned perpendicular to the upper surfaces for microstructural observations and detailed hardness measurements.

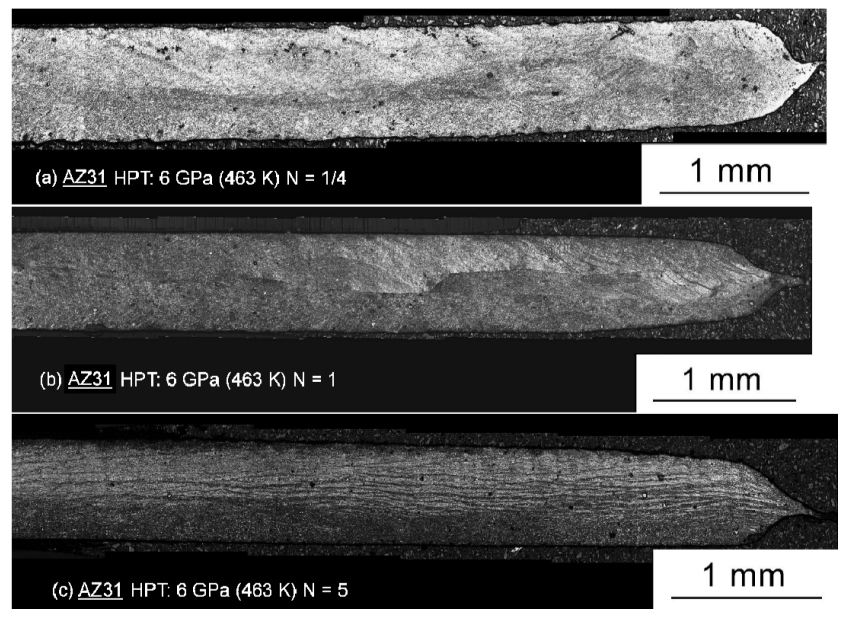

Fig. 5. Flow patterns in the cross-sectional planes of AZ31 samples after processing by HPT (6 GPa, $463 \mathrm{~K}$ ) through (a) $1 / 4$, (b) 1 , and (c) 5 turns at $463 \mathrm{~K}$ [21].

Figure 5 shows vertical sections cut through the disks processed at $463 \mathrm{~K}$ through totals of (a) $1 / 4$ turn, (b) 1 turn, and (c) 5 turns, respectively [21]. It is important to note that the processing temperature of $463 \mathrm{~K}$ is sufficiently high that grain refinement will occur by dynamic recrystallization where new grains are nucleated along grain boundaries and twin boundaries in a necklace-like appearance and these finer grains will gradually spread across the larger grains of the original structure [27, 28]. This means that the distribution of grain sizes will be dependent upon the nature of the deformation associated with the HPT processing. Thus, the occurrence 
of flow localization will be associated with faster deformation rates and with a more refined grain structure. Variations in the grain structure are clearly visible in the vertical cross-sections shown in Fig. 5. Inspection shows there are fully-refined grain structures between the mid-plane of the section and the bottom surface of the disk processed by $1 / 4$ turn in Fig. 5a, near the midplane of the disk processed by 1 turn in Fig. $5 \mathrm{~b}$ and near the bottom surface of the disk processed by 5 turns in Fig. 5c. These observations show, therefore, the development of heterogeneities within the microstructure after processing of the AZ31 alloy by HPT at a temperature of $463 \mathrm{~K}$.

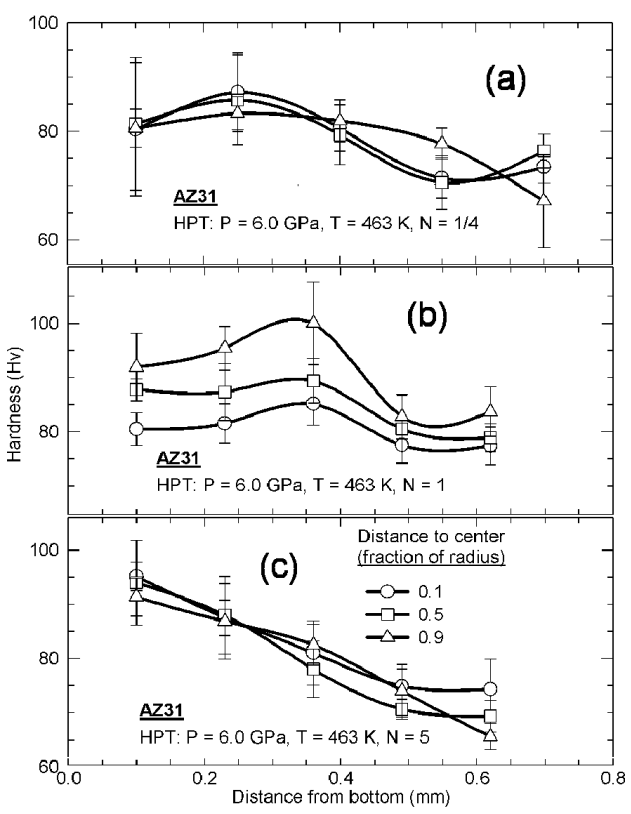

Fig. 6. Microhardness values at various radii as a function of the distance from the bottom of the AZ31 disks after HPT through (a) 1/4, (b) 1, and (c) 5 turns at $463 \mathrm{~K}[21]$.

Hardness measurements were recorded on the vertical planes of the three specimens shown in Fig. 5 and the results are given in Fig. 6 for the samples processed through (a) $1 / 4$ turn, (b) 1 turn and (c) 5 turns, respectively [21]. The results are presented as the Vickers microhardness versus the distance from the bottom surface with individual lines denoting different fractions of the radial distances from the centers of each disk. These plots show significant variations between the different disks although within each disk the results are reasonably consistent for different radial fractions from the centers. Thus, the hardness values are $\mathrm{Hv} \approx 70$ to 90 after $1 / 4$ turn, $\approx 80$ to 100 after 1 turn and $\approx 70$ to 95 after 5 turns. The results provide clear evidence for significant heterogeneity in the disks of the AZ31 alloy processed by HPT with the development of lower hardness values, and therefore larger grain sizes, in the vicinity of the upper surface after higher numbers of turns.

\section{A direct comparison of high-purity Al and the AZ31 Mg alloy}

These results show that the ability to develop homogeneity in the processing of metals by HPT is dependent upon the crystalline structure of the material. In aluminum where slip processes are easy, the material exhibits excellent homogeneity after processing through more than $\approx 5$ revolutions of HPT, whereas in the magnesium AZ31 alloy the numbers of slip systems are limited and there is a high degree of heterogeneity in the processed material. These results are important in view of the current interest in evaluating the degree of structural homogeneity after HPT $[29,30]$ and especially in the demonstrated potential for using hardness data to correlate a universal plot for HPT processing [31].

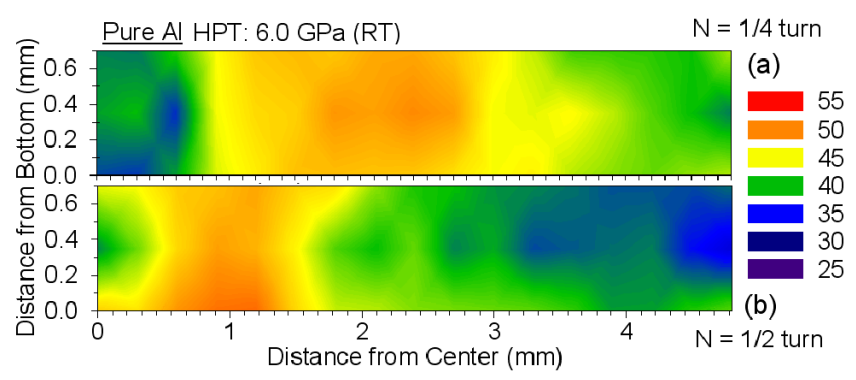

Fig. 7. Distribution of the Vickers microhardness as a function of the location along the half-cross-section of the pure $\mathrm{Al}$ disks after processing by $\mathrm{HPT}$ (6.0 GPa, RT) through (a) $1 / 4$ turn and (b) $1 / 2$ turn.

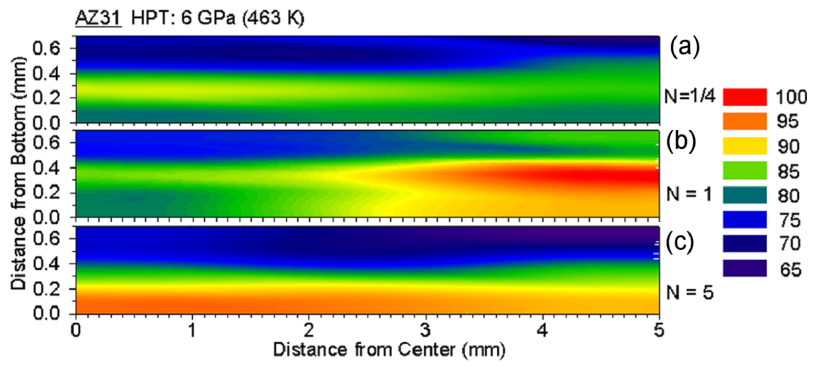

Fig. 8. Distribution of the Vickers microhardness as a function of the location along the half-cross-section of AZ31 disks after processing by HPT (6 GPa, $463 \mathrm{~K}$ ) through (a) $1 / 4$ turn, (b) 1 turn, and (c) 5 turns [20].

For the present results, the two metals used in these experiments are most readily compared by constructing color-coded contour maps showing the variations in the local hardness on planes cut perpendicular to the disk surfaces. Examples of these maps are shown in Fig. 7 for high-purity $\mathrm{Al}$ and in Fig. 8 for the magnesium AZ31 alloy [20]. For aluminum it is apparent that there is no significant hardness variations between the upper and lower surfaces of the disks after processing through $1 / 4$ and $1 / 2$ turn whereas for the AZ31 alloy there are major differences between the two surfaces with a general trend towards higher hardness values near the bottom surfaces of the disks and lower hardness values at the top surfaces. 
These plots show that aluminum and magnesium represent two extremes in terms of microstructural development, with homogeneity developing readily in aluminum but with a high degree of heterogeneity in the magnesium alloy.

Finally, it should be noted there is very recent experimental evidence for the development of unusual shearing patterns in HPT processing including local swirls and vortices that suggest the presence of shear velocity gradients between adjacent positions within the disks [32-35]. More experiments are now needed both to delineate the precise significance of these shearing patterns and to place them within the context of the potential for achieving homogeneity.

\section{Summary and conclusions}

1. Experiments were conducted to evaluate the potential for achieving microstructural homogeneity in high-purity aluminum and a commercial magnesium AZ31 alloy when processing by high-pressure torsion. The degree of homogeneity was evaluated by taking extensive measurements of the Vickers microhardness on planes both parallel to the surfaces of the disks and cut perpendicular to the disk surfaces.

2 . The results show that high-purity aluminum develops excellent homogeneity when processed by more than 5 revolutions in HPT. By contrast, for the magnesium alloy where the number of slip systems is limited, the processed structures show extensive heterogeneity with a tendency for the occurrence of higher hardness values, corresponding to smaller grain sizes, adjacent to the lower surfaces of the disks.

\section{Acknowledgments}

This work was supported in part by the National Science Foundation of the United States under grant No. DMR-0855009 and in part by the European Research Council under ERC grant agreement No. 267464-SPDMETALS.

\section{References}

[1] R.Z. Valiev, T.G. Langdon, Prog. Mater. Sci. 51, 881 (2006).

[2] A.P. Zhilyaev, T.G. Langdon, Prog. Mater. Sci. 53, 893 (2008).

[3] A.P. Zhilyaev, B.K. Kim, G.V. Nurislamova, M.D. Baró, J.A. Szpunar, T.G. Langdon, Scr. Mater. 46, 575 (2002).

[4] A.P. Zhilyaev, G.V. Nurislamova, B.K. Kim, M.D. Baró, J.A. Szpunar, T.G. Langdon, Acta Mater. 51, 753 (2003).

[5] A.P. Zhilyaev, B.K. Kim, J.A. Szpunar, M.D. Baró, T.G. Langdon, Mater. Sci. Eng. A 381, 377 (2005).

[6] R.Z. Valiev, Yu.V. Ivanisenko, E.F. Rauch, B. Baudelet, Acta Mater. 44, 4705 (1996).

[7] F. Wetscher, A. Vorhauer, R. Stock, R. Pippan, Mater. Sci. Eng. A 387-389, 809 (2004).

[8] F. Wetscher, R. Pippan, S. Sturm, F. Kauffmann, C. Scheu, G. Dehm, Metall. Mater. Trans. A 37, 1963 (2006).

[9] A.P. Zhilyaev, S. Lee, G.V. Nurislamova, R.Z. Valiev, T.G. Langdon, Scr. Mater. 44, 2753 (2001).
[10] A. Vorhauer, R. Pippan, Scr. Mater. 51, 921 (2004).

[11] A.P. Zhilyaev, K. Oh-ishi, T.G. Langdon, T.R. McNelley, Mater. Sci. Eng. A 410-411, 277 (2005).

[12] C. Xu, Z. Horita, T.G. Langdon, Acta Mater. 55, 203 (2007).

[13] C. Xu, Z. Horita, T.G. Langdon, Acta Mater. 56 , 5168 (2008).

[14] M. Kawasaki, T.G. Langdon, Mater. Sci. Eng. A 498, 341 (2008).

[15] M. Kawasaki, B. Ahn, T.G. Langdon, Acta Mater. 58, 919 (2010).

[16] M. Kawasaki, B. Ahn, T.G. Langdon, J. Mater. Sci. 45, 4583 (2010).

[17] Z.C. Duan, X.Z. Liao, M. Kawasaki, R.B. Figueiredo, T.G. Langdon, J. Mater. Sci. 45, 4621 (2010).

[18] Y. Estrin, A. Molotnikov, C.H.J. Davies, R. Lapovok, J. Mech. Phys. Solids. 56, 1186 (2008).

[19] M. Kawasaki, R.B. Figueiredo, T.G. Langdon, Acta Mater. 59, 308 (2010).

[20] R.B. Figueiredo, T.G. Langdon, Mater. Sci. Eng. A 528, 4500 (2011).

[21] R.B. Figueiredo, M.T.P. Aguilar, P.R. Cetlin, T.G. Langdon, Metall. Mater. Trans. A 42, 3013 (2011).

[22] C. Xu, Z. Horita, T.G. Langdon, Mater. Trans. 51, $2(2010)$.

[23] K. Edalati, Z. Horita, T.G. Langdon, Scr. Mater. 60, 9 (2009).

[24] A. Yamashita, Z. Horita, T.G. Langdon, Mater. Sci. Eng. A 300, 142 (2001).

[25] R.B. Figueiredo, P.R. Cetlin, T.G. Langdon, Acta Mater. 55, 4769 (2007).

[26] P.R. Cetlin, M.T.P. Aguilar, R.B. Figueiredo, T.G. Langdon, J. Mater. Sci. 45, 4561 (2010).

[27] R.B. Figueiredo, T.G. Langdon, J. Mater. Sci. 44, 4758 (2009).

[28] R.B. Figueiredo, T.G. Langdon, J. Mater. Sci. 45, 4827 (2010).

[29] A. Hohenwarter, A. Bachmaier, B. Gludovatz, S. Scheriau, R. Pippan, Int. J. Mater. Res. 100, 1653 (2009).

[30] D. Geist, C. Rentenberger, H.P. Karnthaler, Acta Mater. 59, 4578 (2011).

[31] K. Edalati, Z. Horita, Mater. Trans. 51, 1051 (2010).

[32] Y. Cao, Y.B. Wang, S.N. Alhajeri, X.Z. Liao, W.L. Zheng, S.P. Ringer, T.G. Langdon, Y.T. Zhu, J. Mater. Sci. 45, 765 (2010).

[33] Y. Cao, M. Kawasaki, Y.B. Wang, S.N. Alhajeri, X.Z. Liao, W.L. Zheng, S.P. Ringer, Y.T. Zhu, T.G. Langdon, J. Mater. Sci. 45, 4545 (2010).

[34] Y.Z. Tian, X.H. An, S.D. Wu, Z.F. Zhang, R.B. Figueiredo, N. Gao, T.G. Langdon, Scr. Mater. 63, 65 (2010).

[35] Y. Cao, Y.B. Wang, R.B. Figueiredo, L. Chang, X.Z. Liao, M. Kawasaki, W.L. Zheng, S.P. Ringer, T.G. Langdon, Y.T. Zhu, Acta Mater. 59, 3903 (2011). 